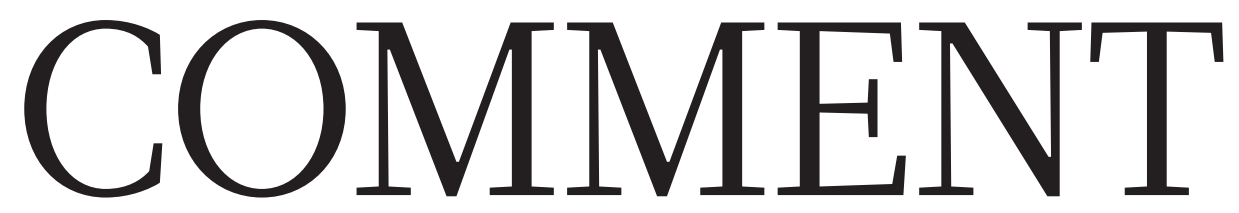

PALAEONTOLOgy How teeth, diet and environment shaped human evolution $\mathbf{p . 2 6}$
MICROBIOLOGY A life of Frederick Novy, forgotten bacteriology and education pioneer $\mathbf{p . 2 8}$
PUBLISHING A call for one submission system to rule them all p.30
SUSTAINABILITY Restore

earthworm workforce to rebuilt topsoil p.30

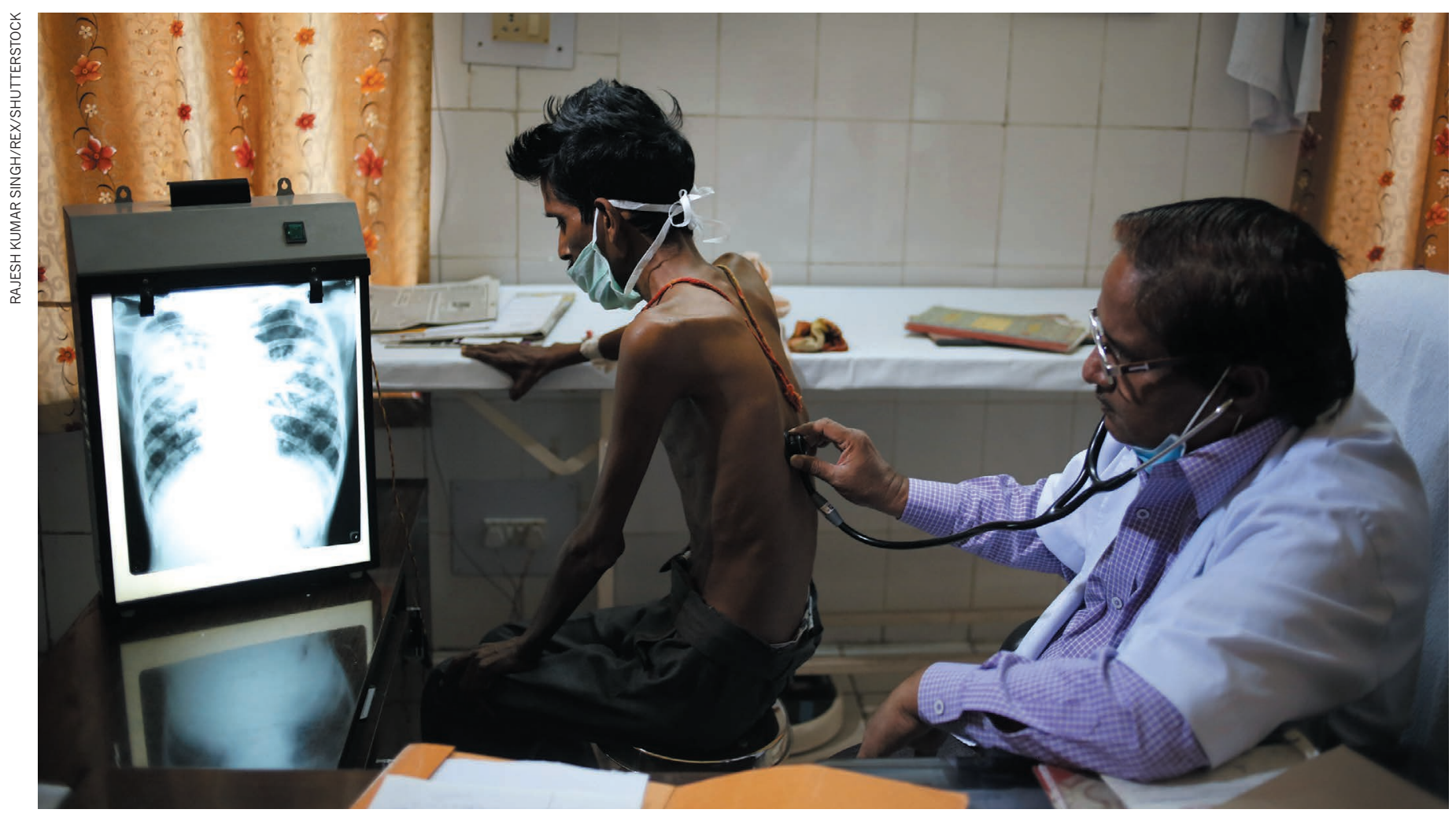

A physician examines a man with TB. Like the bacteria behind other common infections, Mycobacterium tuberculosis has become increasingly resistant to drugs.

\title{
Antibiotic resistance has a language problem
}

A failure to use words clearly undermines the global response to antimicrobials' waning usefulness. Standardize terminology, urge Marc Mendelson and colleagues.

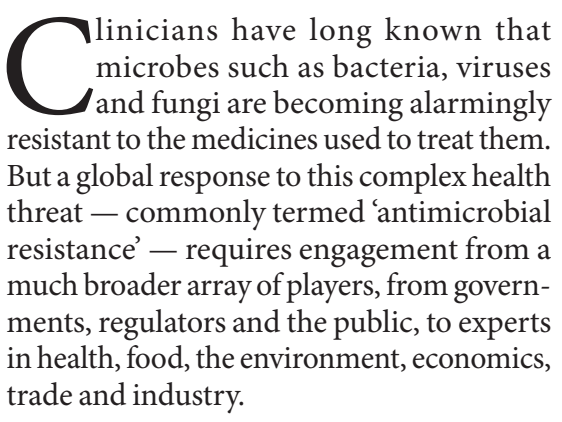

People from these disparate domains are talking past each other. Many of the terms routinely used to describe the problem are misunderstood, interpreted differently or loaded with unhelpful connotations.

On 16 March, the United Nations formed an interagency group to coordinate the fight against drug resistance ${ }^{1}$. We urge that, as one of its first steps, this group coordinate a review of the terminology used by key actors. Such an effort could improve understanding across the board and help to engender a consistent and focused global response.

\section{BLINDED BY SCIENCE}

A 2015 survey by the World Health Organization (WHO) in 12 countries highlighted people's unfamiliarity with the language of antibiotic resistance ${ }^{2}$. Fewer than half of the nearly 10,000 respondents had heard of the term 'antimicrobial resistance'. Only one-fifth were aware of its abbreviated form 'AMR'. 
By contrast, more than two-thirds knew of the terms 'antibiotic resistance' or 'drug resistance'. A similar study published the same year of people in the United Kingdom - by the UK biomedical charity the Wellcome Trust - revealed comparable trends ${ }^{3}$.

The interchangeable use of terms by the press and by scientists in publications and meetings is likely to be counterproductive in all sorts of contexts. Take food production. In recent years, different sectors have called on countries to phase out or abolish the 'antimicrobials' used to promote animal growth, to protect humans from increasing levels of drug-resistant bacteria ${ }^{4}$.

But, by definition, antimicrobials include medicines that play a crucial part in sustaining current levels of poultry production worldwide by reducing the gut inflammation caused by coccidian parasites. Anticoccidial medicines have no effect on bacteria, and do not drive bacterial resistance in humans or other animals. So a demand to abolish all antimicrobials for growth promotion misses the point and could potentially harm food security.

Simple, clear and unambiguous terminology would help to ensure that the global effort against drug resistance is focused on the greatest immediate challenge: the rise of drug-resistant bacteria that cause common illnesses, resulting from the high use of antibiotics by humans. It could also improve people's understanding and engagement. The Wellcome Trust study found that citizens either don't understand the language that scientists and the media use in relation to antibiotic resistance, or they resist engaging with the problem because they feel powerless to do anything about it.

\section{WORD POWER}

Words matter. A 2015 study ${ }^{5}$ of word use in social-media networks, for instance, indicated that the terms 'climate change' and 'global warming' have differing effects on knowledge and awareness. Likewise, a 2013 survey ${ }^{6}$ suggested that 'global warming' is more likely than 'climate change' to prompt Americans to support large and small-scale US efforts to address the problem - presumably because the phrase imparts a greater sense of personal threat.

Similarly, use of the term 'second-hand smoke' in the past 40 years has been crucial to communicating the risks of smoking to the public ${ }^{7}$. And the decision to name the cause of AIDS as human immunodeficiency virus (HIV) in 1986 - instead of human T-cell lymphotropic virus (HTLV-III) or lymphadenopathy-associated virus (LAV) - helped people to understand that the disease was caused by a virus that harms the immune system. As such, it was crucial in tackling stigma and phasing out terms such as 'the gay plague', which had previously

dominated communication around AIDS.

The appointment of the United Nations Interagency Group provides an opportunity to apply the power of words to drug resistance. We urge this group to focus on three key issues.

Drug-resistant infection. We propose that this be the overarching term used (in English) to describe infections caused by organisms that are resistant to treatment, including those caused by bacteria that do not respond to antibiotics. The WHO and Wellcome Trust surveys indicate that most people understand this term, and it is already in use for tuberculosis. (Medical practitioners, among others, commonly refer to 'drug-resistant tuberculosis.) We also suggest that

"War and threat
were once
potent rallying
calls. But a
more nuanced,
ballanced,
standardized
vocabulary is
now needed."
more-specific words such as 'antibiotic' or 'antifungal' are used in preference to 'antimicrobial' when referring to medicines against a specific type of organism.

Stewardship. This frequently comes up in discussions about drug resistance. Specifically, it refers to how the appropriate use of antibiotics can maximize both their current effects and the chances of their being available for future generations. But the term is invariably used too narrowly.

Historically, antibiotic stewardship has been conducted as part of hospital programmes, and many people use it to refer to the actions of infection specialists and pharmacists. Today, its practice is much broader (see 'Many meanings').
Antibiotic stewardship can be an individual, multidisciplinary, hospital or communitylevel commitment to ensuring appropriate antibiotic use for those patients or animals that have a bacterial infection that requires treatment, and ensuring that all aspects of the prescription (dose, duration and so on) are as they should be. At the other end of the scale, the WHO is now working on developing a global stewardship framework - potentially akin to the WHO Framework Convention on Tobacco Control.

Furthermore, 'conservation' is often used interchangeably with stewardship. But the term has a broader meaning, also encapsulating the prevention of infection in the first place, for instance through vaccination or by improving water quality and sanitation.

War. Much of the rhetoric around drug resistance has pitched humans in a fight against bacteria. For instance, people frequently refer to 'the war against superbugs', or the 'fight against AMR'. Also - in the pursuit of an enemy - responsibility for the increase of antibiotic-resistant bacteria in humans is often placed at the door of animal-health professionals, the livestock industry, farmers and veterinary surgeons.

This blame narrative is unhelpful. The use of antibiotics in animals selects out bacteria that are resistant to the drugs. And those resistant bacteria can be transferred from farm to fork. But the predominant driver of antibiotic resistance in humans is the intense pressure exerted by the misuse and overuse of antibiotics in people.

The war narrative also fails to recognize our symbiotic relationships with bacteria. The more we go on the 'attack', the more likely we are to interrupt the vital roles of bacteria in our guts and airways and on our skin. Around 100 trillion bacteria live in our

\section{MANY MEANINGS}

'Antibiotic stewardship' could refer to one of six endeavours; most people use it to describe the actions of physicians and pharmacists.

\begin{tabular}{|c|c|}
\hline Type & Features \\
\hline Individual & $\begin{array}{l}\text { Systematic approach taken by drug prescriber to optimize use to improve } \\
\text { patient outcome, ensure patient safety and limit emergence of resistance. }\end{array}$ \\
\hline Multidisciplinary & $\begin{array}{l}\text { Any combination of infection specialists, microbiologists, non-specialist } \\
\text { clinicians, pharmacists, infection-prevention officers and nurses, or of veterinary } \\
\text { surgeons and para-veterinary professionals (in animal health), working in a team } \\
\text { to optimize use of one or more antibiotics for a patient or patients. }\end{array}$ \\
\hline Hospital (institutional) & Involves one or more teams, usually coordinated by a committee. \\
\hline Community & $\begin{array}{l}\text { At primary health clinics, single or group practices, long-term care facilities or, in } \\
\text { animal health, at single farms or farm groups. }\end{array}$ \\
\hline National & $\begin{array}{l}\text { Activities encompass broader issues, using legislation and regulation to define } \\
\text { access to medicines and who may prescribe them. }\end{array}$ \\
\hline Global & $\begin{array}{l}\text { Linked to development, this will expand on national programmes, to coordinate } \\
\text { individual nations, country and regional networks and continental activities. } \\
\text { The World Health Organization is working on "a global stewardship framework } \\
\text { to support the development, control, distribution and appropriate use of new } \\
\text { antibiotics, diagnostic tools, vaccines and other interventions, with linkage to } \\
\text { new model/s of research and development". }\end{array}$ \\
\hline
\end{tabular}




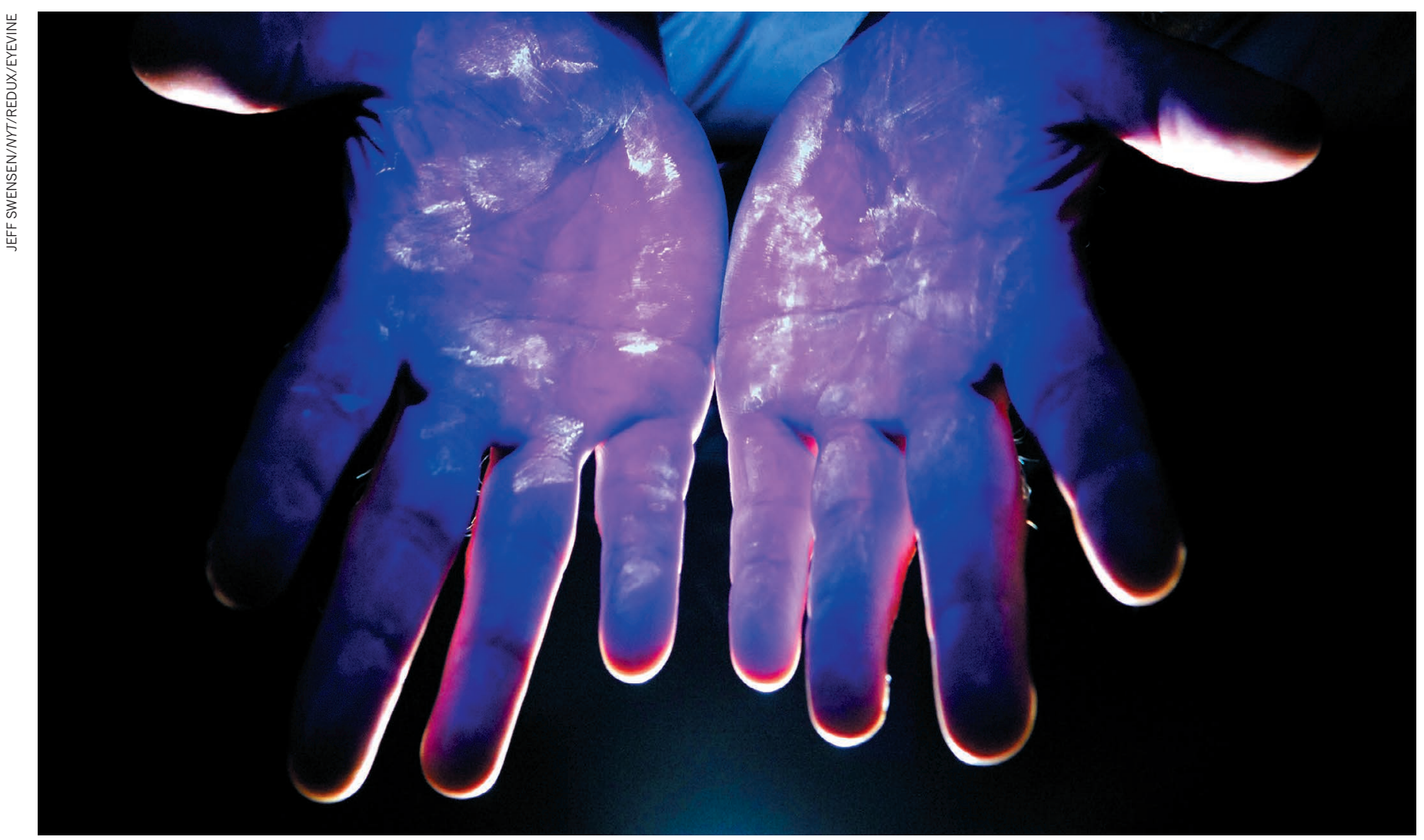

Aggressive tactics to stop the spread of pathogens such as methicillin-resistant Staphylococcus aureus will benefit from a united front in terminology.

intestines alone, and most of these help us to stay in good health.

War and threat were once potent rallying calls. But a more nuanced, balanced, standardized vocabulary is now needed - one that takes ecological balance into account.

\section{ACTIONS SPEAK LOUDER}

Because terminology has geographic, disciplinary and societal variations that affect understanding and interpretation, a programme of research is needed to optimize the lexicon across different countries and languages. Such a programme could be undertaken within the current WHO global action plan objective 1 - to improve awareness and understanding of drug resistance through effective communication, education and training.

Such a research programme could identify the terms used globally and establish whether the direct translation of English words into other languages renders them useful. The term drug-resistant infection is not used in France, for instance, nor is the translation of antimicrobial resistance - résistance aux antimicrobiens. Rather, antibiorésistance, a contraction for antibiotic resistance, is preferred. It could also explore how such phrases are interpreted by people from different walks of life, assess the impact of different language on understanding and on rates of infection, build a global consensus around the scientific terminology of drug resistance and integrate these terms into global education programmes and communication strategies.

William Shakespeare was the master of multiple meaning. Juliet's "What's in a name ..." muse about her Romeo riffs on the arbitrary, insubstantial nature of labels. But, given the gravity of what's ahead, now is the time consider the power of words to change the course of events. It is a lesson that those of us trying to broadcast an understanding of this crisis should heed.

Marc Mendelson is professor of infectious diseases and head of the Division of Infectious Diseases \& HIV Medicine at Groote Schuur Hospital, University of Cape Town, South Africa. Manica Balasegaram is director of the Global Antibiotic Research and Development Partnership, Drugs for Neglected Diseases Initiative, Geneva, Switzerland. Tim Jinks is head of the Drug-Resistant Infections Program at the Wellcome Trust, London, UK. Céline Pulcini is professor of infectious diseases at Nancy University Hospital and leads a research team on stewardship at the University of Lorraine (EA 4360 APEMAC) in Nancy, France. Mike Sharland is professor of paediatric infectious diseases at the Institute of Infection and Immunity, St Georges Hospital, University of London, UK. e-mail:marc.mendelson@uct.ac.za
1. UN News Centre. 'UN announces interagency group to coordinate global fight against antimicrobial resistance' (2017); available at http://go.nature.com/2pcqx28

2. World Health Organization Antibiotic Resistance: Multi-Country Public Awareness Survey (WHO, 2015); available at http://go.nature. com/2ptdypm

3. Wellcome Trust Exploring the Consumer Perspective on Antimicrobial Resistance (Wellcome Trust, 2015); available at http:// go.nature.com/2pkwcbw

4. The Review on Antimicrobial Resistance Tackling Drug-resistant Infections Globally: Final Report and Recommendations (HM Government/Wellcome Trust, 2016); available at http://go.nature. com/2oj9uan

5. Lineman, M., Do, Y., Kim, J. Y. \& Joo, G.-J. PLoS ONE 10, e0138996 (2015).

6. Leiserowitz, A. et al. What's In A Name? Global Warming Versus Climate Change (Yale Project on Climate Change Communication/George Mason University Center for Climate Change Communication, 2014); available at http:// go.nature.com/2pubszd

7. Viet Nam News 'Campaign launched against secondhand smoke' (2016); available at http:// go.nature.com/2oqotcb

C.P. declares competing financial interests; see go.nature.com/2q4k4ps for details.

\section{CORRECTION}

The print version of the Comment 'Five hacks for digital democracy' (B. S. Noveck Nature 544, 287-289; 2017) failed to note that the author declared competing financial interests. See go.nature. com/2ocprj6 for the statement. 